Pesq. Vet. Bras. 35(3):291-296, março 2015 DOI: $10.1590 / \mathrm{S} 0100-736 \mathrm{X} 2015000300013$

\title{
Desempenho e morfologia intestinal de frangos de corte na fase de crescimento, com e sem adição de nucleotídeos na dieta, em diferentes níveis proteicos ${ }^{1}$
}

\author{
Juliana C. Faveri²*, Alice E. Murakami ${ }^{3}$, Alexandra Potença ${ }^{3}$, Cínthia Eyng ${ }^{3}$, \\ Ana Flávia Q. Marques ${ }^{3}$ e Tatiana Carlesso dos Santos ${ }^{3}$
}

\begin{abstract}
Faveri J.C., Murakami A.E., Potença A., Eyng C., Marques A.F.Q. \& Santos T.C. 2015. [Performance and morphology of the intestinal mucosa of broilers during growth, with or without nucleotides, at different protein levels.] Desempenho e morfologia intestinal de frangos de corte na fase de crescimento, com e sem adição de nucleotídeos na dieta, em diferentes níveis protéicos. Pesquisa Veterinária Brasileira 35(3):291-296. Departamento de Zootecnia, Programa de Pós-Graduação em Zootecnia, Universidade Estadual de Maringá, Av. Colombo 5790, Maringá, PR 87020-900, Brazil. E-mail: jufaveri@yahoo.com.br

The experiment was conducted to evaluate the performance and intestinal morphology of growing broilers, with and without addition of nucleotides in the diet at different protein levels. A total of 868 21-day-old male Cobb broiler chicks were used in a completely randomized design. The diets were: control with high crude protein $(18.86 \%)$ and low crude protein (16.80\%), both without nucleotides, meeting the requirement of $1.062 \%$ digestible lysine; and five treatments with the addition of $0.5 \mathrm{~kg}$ of nucleotides/ton of feed, with different levels of digestible lysine $(1.262 \%, 1.162 \%, 1.062 \%, 0962 \%$ and $0.862 \%)$, all formulated based on the low-protein diet (16.80\%), with four replications each. Feed intake (g) decreased linearly $(P \leq 0.05)$ in the period from 20 to 27,20 to 35 , and 20 to 42 days of age; feed intake decreased by increasing levels of lysine in the diet. Feed-to-gain ratio showed a quadratic effect $(\mathrm{P} \leq 0.05)$ for birds of the period from 20 to 27,20 to 35 and 20 to 42 days of age, decreasing as levels of digestible lysine increased, with minimum levels reaching $1.119 \%, 1.187 \%$ and $1.132 \%$ digestible lysine, respectively. The diet with $1.062 \%$ of lysine did not differ $(\mathrm{P}>0.05)$ from the negative control for villus height and crypt depth in the duodenum.
\end{abstract}

INDEX TERMS: Intestinal mucosa, histologic analysis, ideal protein, nucleotides, broilers.

RESUMO.- 0 experimento foi conduzido com o objetivo de avaliar o desempenho e a morfologia intestinal de frangos de corte na fase de crescimento, com e sem adição de nucleotídeos na dieta, em diferentes níveis proteicos. Foram utilizados 868 pintos de cortes machos de 21 dias de idade, da linhagem Cobb, submetidos a um delineamento inteiramente casualizado. As dietas foram compostas por

\footnotetext{
${ }^{1}$ Recebido em 20 de maio de 2014.

Aceito para publicação em 8 de março de 2015

Parte da Dissertação de Mestrado do primeiro autor.

${ }^{2}$ Departamento de Zootecnia, Universidade Federal da Bahia (UFBA), Av. Adhemar de Barros 500, Ondina, Salvador, BA 40170-110, Brasil *Autor para correspondência: jufaveri@yahoo.com.br

${ }^{3}$ Departamento de Zootecnia, Universidade Estadual de Maringá (UEM), Av. Colombo 5790, Maringá, PR 87020-900, Brasil.
}

dois controles, de alta e baixa proteína bruta, com 18,86\% e $16,80 \%$ respectivamente, com a exigência de $1,062 \%$ de lisina digestível. Tendo como base a dieta controle de baixa proteína foram traçados mais cinco tratamentos com adição de $0,5 \mathrm{~kg}$ de nucleotídeos/ton de ração, e diferentes níveis de lisina digestível: 1,262\%, 1,162\%,1,062\%, 0962\% e $0,862 \%$, com quatro repetições cada. 0 consumo alimentar (g) diminuiu linearmente $(\mathrm{P} \leq 0,05)$ no período de 20 a 27 , de 20 a 35 e de 20 a 42 dias de idade, em que aumentando os níveis de lisina digestível na dieta, observou-se diminuição no consumo de ração. A conversão alimentar teve efeito quadrático $(P \leq 0,05)$ para as aves do período de 20 a 27 , de 20 a 35 e de 20 a 42 dias de idade, diminuindo à medida que os níveis de lisina digestível aumentaram, atingindo o mínimo com 1,119, 1,187 e 1,132\% de lisina digestível, res- 
pectivamente. A dieta com 1,062\% de lisina digestível não diferiu $(\mathrm{P}>0.05)$ da dieta controle com alta proteína, para altura das vilosidades e profundidade de cripta, no duodeno, ilustrando então efeito benéfico do uso de nucleotídeos em dietas com baixa proteína bruta.

TERMOS DE INDEXAÇÃO: Mucosa intestinal, morfologia intestinal, nucleotídeos, proteína ideal, frangos de corte.

\section{INTRODUÇÃO}

Com os avanços das preocupações dos consumidores em estarem consumindo carnes com resíduos de antibióticos e assim adquirirem resistência bacteriana, as indústrias produtoras da carne de frango foram impulsionadas a aderirem a novos produtos que possam agir como agentes profiláticos em sistemas de criação intensiva.

Dentre estes se destacam os nucleotídeos que podem agir como uma alternativa aos antibióticos na alimentação de animais jovens (Mateo et al. 2004). Os nucleotídeos participam da divisão celular, do crescimento da célula, da modulação do sistema imunológico e podem ajudar na manutenção da saúde intestinal, reduzindo a incidência de doenças entéricas (Turner et al. 2001). Sabe-se que o desenvolvimento da mucosa intestinal é decorrente de dois eventos citológicos primários associados: renovação celular (proliferação e diferenciação), resultante das divisões mitóticas sofridas por células totepotentes localizadas na cripta e ao longo dos vilos e a perda de células por descamação (extrusão), que ocorre naturalmente no ápice dos vilos (Uni 2000).

A suplementação com nucleotídeos é especialmente importante no desenvolvimento destes tecidos com rápido turnover celular, tanto quanto a capacidade de síntese endógena não é suficiente para responder às maiores necessidades, como em períodos de rápido crescimento e após agressões no organismo, tais como doenças ou traumas (Bueno et al. 1994). Além disso, o metabolismo de nucleotídeos é responsável pela liberação de bases nitrogenadas e expressão gênica, sendo sua suplementação de forma sintética uma alternativa interessante ao encurtar o processo de transcrição da informação para produção de carne e ovos, ou seja, pode-se argumentar uma possível relação entre o requerimento de proteína para o animal e a suplementação de nucleotídeos.

Os avanços na nutrição aliada com avanços no manejo e melhoramento genético possibilitaram a utilização de rações melhor balanceadas, pois se tem como base hoje em dia o conceito de proteína ideal e não mais a proteína bruta. Formulando rações no conceito da proteína ideal o animal receberá uma dieta com um perfil de aminoácidos nas proporções exatas ao seu requerimento, ou seja, a suplementação de aminoácidos digestíveis é feita de forma a fornecer um balanceamento ótimo destes aminoácidos, sem excesso ou deficiência de suas necessidades absolutas (Bertechini 2006).

Assim, este estudo teve como objetivo avaliar o desempenho e a morfologia intestinal de frangos de corte na fase de crescimento, com e sem adição de nucleotídeos na dieta, em diferentes níveis proteicos.

\section{MATERIAL E MÉTODOS}

O experimento foi conduzido no Setor de Avicultura da Fazenda Experimental de Iguatemi da Universidade Estadual de Maringá, sob aprovação do Comitê de Ética em Experimentação Animal (CEEA/UEM, Registro no. 047/2006), no mês de outubro de 2009.

Foram utilizados 868 pintos de cortes machos de 21 dias de idade, da linhagem Cobb. As dietas foram compostas por dois controles, de alta e baixa proteína bruta, com 18,86\% e 16,80\% respectivamente, com a exigência de $1,062 \%$ de lisina digestível. Tendo como base a dieta controle de baixa proteína foram traçados mais cinco tratamentos com adição de 0,5 kg de nucleotídeos/ton de ração, e diferentes níveis de lisina digestível: 1,262\%, $1,162 \%, 1,062 \%, 0962 \%$ e $0,862 \%$, com quatro repetições cada. $\mathrm{Na}$ formulação da dieta com $0,862 \%$ de lisina digestível não foi possível alcançar o nível de proteína estipulado, portanto a dieta apresentou 15,98\% de proteína bruta. A composição das rações experimentais encontra-se no Quadro 1. O produto usado como fonte de nucleotídeos foi o PSB Complex - Ascogen $₫$, com $45 \%$ de proteína bruta, 2,2\% de gordura, máximo de 3,0\% de fibra bruta, $7,2 \%$ de cinza e $24 \%$ de nucleotídeos totais. Atendendo à recomendação de $0,5 \mathrm{~kg}$ Ascogen/ton de ração para frangos de corte de 21 a 42 dias de idade.

O programa de luz foi contínuo, durante os primeiros dez dias e o restante do período com $23 \mathrm{~h}$ de luz/dia. Usou-se cama de maravalha de primeiro lote, água e ração fornecidas ad libitum durante todo o período experimental, sendo estas formuladas de modo a atender às exigências nutricionais, de acordo com as recomendações de Rostagno et al. (2005). As temperaturas médias (máxima e mínima) dentro do galpão foram de 35 e 17 ํㅡ, respectivamente, com umidade relativa média de $75 \%$. 0 percentual de viabilidade registrado durante todo o período experimental foi de $99,2 \%$. Os frangos foram pesados, semanalmente, para calcular as seguintes variáveis: peso corporal, ganho de peso, consumo de ração e conversão alimentar.

Aos 35 dias de idade foram abatidas oito aves por tratamento, onde se coletou o fígado, o intestino delgado e o intestino grosso. 0 fígado foi pesado imediatamente após ter sido retirado. Após remoção dos intestinos, delgado e grosso, estes foram separados por secções no local onde o duodeno emerge da moela e no início do ceco, sendo posteriormente pesados e medidos. 0 comprimento do intestino grosso foi considerado como o comprimento do cólon e reto somado ao comprimento dos cecos. Para as análises histológicas, foram colhidos segmentos de três centímetros do duodeno, do jejuno e do íleo de oito aves por tratamento. Esses foram cortados transversalmente e longitudinalmente, abertos pela sua borda mesentérica, lavados e estendidos pela túnica serosa, os quais foram fixados em solução de formol a $10 \%$ por $24 \mathrm{~h}$.

Posteriormente, foram transferidos para álcool 70\%, desidratados em uma série crescente de alcoóis, diafanizados em xilol e incluídos em parafina. Com o uso do micrótomo foram obtidos cortes de sete micrometros $(\mu \mathrm{m})$ de espessura, os quais foram corados com a técnica de hematoxilina e eosina. Nestes cortes, com microscópio ótico acoplado a um sistema analisador de imagens (Motic Images Plus 2.0) e a um computador, foram medidas a altura das vilosidades e a profundidade das criptas, para determinação da relação vilosidade/cripta. As medidas de altura das vilosidades foram tomadas a partir da região basal coincidente com a porção superior das criptas, de sua base até a região de transição cripta: vilosidade (Loddi 1998).

Aos 42 dias de idade, para o rendimento de carcaça e seus respectivos cortes, oito aves de cada tratamento (duas aves/box) foram submetidas a jejum alimentar por $6 \mathrm{~h}$ e abatidas através de atordoamento por choque elétrico (220W) e posterior sangria, que foi efetuada no abatedouro experimental na Universidade Es- 
Quadro 1. Composição e valores calculados das rações para a fase crescimento (21-42 dias de idade)

\begin{tabular}{|c|c|c|c|c|c|c|c|}
\hline \multirow[t]{2}{*}{ Ingredientes \% } & \multicolumn{2}{|c|}{ Controle } & \multicolumn{5}{|c|}{ Níveis de lisina (\%) } \\
\hline & Alta PB & Baixa PB & $0,862 \%$ & $0,962 \%$ & $1,062 \%$ & $1,162 \%$ & $1,262 \%$ \\
\hline Milho grão & 65,04 & 72,45 & 74,54 & 72,02 & 72,45 & 72,88 & 73,30 \\
\hline Soja farelo $45 \%$ & 28,03 & 21,21 & 20,21 & 22,07 & 21,21 & 20,35 & 19,49 \\
\hline Fosfato bicálcio & 1,82 & 1,86 & 1,86 & 1,85 & 1,86 & 1,87 & 1,87 \\
\hline Calcário & 0,84 & 0,87 & 0,88 & 0,87 & 0,87 & 0,87 & 0,87 \\
\hline Óleo de soja & 2,95 & 1,60 & 1,38 & 1,76 & 1,60 & 1,44 & 1,28 \\
\hline Suplemento Mineral ${ }^{\mathrm{a}}$ & 0,050 & 0,050 & 0,050 & 0,050 & 0,050 & 0,050 & 0,050 \\
\hline Suplemento Vitamínico ${ }^{\text {b }}$ & 0,100 & 0,100 & 0,100 & 0,100 & 0,100 & 0,100 & 0,100 \\
\hline Sal comum & 0,400 & 0,400 & 00 & 0,400 & 0,400 & 0,400 & 0,400 \\
\hline Dl-metionina-98\% & 0,245 & 0,298 & 0,156 & 0,216 & 0,298 & 0,380 & 0,462 \\
\hline L-lisina HCl-99\% & 0,285 & 0,489 & & 0,333 & 0,489 & 0,645 & 0,801 \\
\hline L-treonina- & 0,079 & 0,1 & 2 & 0,090 & 0,175 & 0,260 & 0,346 \\
\hline L-triptofano - 98\% & 0,000 & 0,039 & 0,004 & 0,013 & 0,039 & 0,063 & 0,089 \\
\hline L-valina & 0,060 & 0,164 & 0,021 & 0,072 & 0,164 & 0,255 & 0,347 \\
\hline L-argin & 0,0 & 0,1 & & 0,059 & 99 & 39 & 0,480 \\
\hline Inerte & 0,100 & 0,100 & 0,050 & 0,050 & 0,050 & 0,050 & 0,050 \\
\hline ucleotídeos & 0,000 & 0,000 & 0,0 & 0,050 & 0,050 & 0,050 & 0,050 \\
\hline Total & 100,00 & 100 & 00 & 100,00 & 100,00 & 100,00 & 100,00 \\
\hline \multicolumn{8}{|l|}{ Valores calculados } \\
\hline Proteína bruta (\%) & 18,86 & & & 16,80 & 16,80 & 16,80 & 16,80 \\
\hline t.aves (kcal/kg) & 3,15 & 3,15 & & 3,15 & 3,15 & 3,15 & 3,15 \\
\hline Cálci & 0,88 & 0,88 & 0,88 & 0,88 & 0,88 & 0,88 & 0,88 \\
\hline Fósf & 0,44 & 0,44 & 0,44 & 0,44 & 0,44 & 0,44 & 0,44 \\
\hline dig. $(\%)$ & 0,765 & 0,765 & 0,621 & 0,693 & 0,765 & 0,837 & 0,909 \\
\hline Lisin & 1,062 & 1,062 & 0,862 & 0,962 & 1,062 & 1,162 & 1,262 \\
\hline ina dig. $(\%)$ & 0,690 & 0,690 & 0,560 & 0,625 & 0,690 & 0,755 & 0,820 \\
\hline Triptofano dig. (\%) & 0,199 & 0,199 & 0,161 & 0,180 & 0,199 & 0,217 & 0,236 \\
\hline Valina dig. (\%) & 0,818 & 0,818 & 0,664 & 0,741 & 0,818 & 0,895 & 0,972 \\
\hline dig. (\%) & 1,118 & 1,115 & 0,905 & 1,010 & 1,115 & 1,220 & 1,325 \\
\hline Histidina dig. (\%) & 0,460 & 0,404 & 0,399 & 0,413 & 0,404 & 0,396 & 0,388 \\
\hline Isoleucina dig. (\%) & 0,780 & 0,658 & 0,643 & 0,675 & 0,658 & 0,641 & 0,624 \\
\hline Sódio (\%) & 0,197 & 0,195 & 0,195 & 0,195 & 0,195 & 0,194 & 0,194 \\
\hline \multicolumn{8}{|c|}{$\begin{array}{l}\text { Suplemento mineral (Conteúdo por kg de premix): Ferro } 10.000,00 \mathrm{mg} \text {; Cobre } 16.000,00 \mathrm{mg} \text {; Iodo } \\
\text { 2.400,00mg; Zinco } 100.000,00 \mathrm{mg} \text {; Manganês } 140.000,00 \mathrm{mg} \text {; Selênio 400,00mg; Veículo q.s.p. } \\
\text { 1.000,00g. }\end{array}$} \\
\hline \multicolumn{8}{|c|}{$\begin{array}{l}\text { b Suplemento Vitamínico Inicial (Conteúdo por kg de premix): Vit. A 7.000.000,00 UI; Vit. D3 } \\
\text { 2.200.000,00 UI; Vit.E 11.000,00mg; Vit. K3 1.600,00mg; Vit. B1 2.000,00mg; Vit. B2 5.000,00mg, } \\
\text { Vit. B12 12.000,00mcg; Niacina 35.000,00mg; Ácido Pantotênico 13.000,00mg; Ácido Fólico } \\
\text { 800,00mg; Antioxidante 100.000,00; Veículo q.s.p. 1.000,00g. }\end{array}$} \\
\hline \multicolumn{8}{|c|}{$\begin{array}{l}{ }^{c} \text { Fonte de nucleotídeos, Ascogen }{ }^{\circledR} \text { (PSB Complex, Ascogen). Recomendação para fase de cresci- } \\
\text { mento }(0,05 \mathrm{~kg} / \text { ton de ração). }\end{array}$} \\
\hline
\end{tabular}

tadual de Maringá. Para o cálculo do rendimento de carcaça, foi considerado o peso da carcaça eviscerada, sem os pés, cabeça e gordura abdominal, em relação ao peso vivo das aves, que foram pesadas individualmente antes do abate. Para o rendimento dos cortes nobres, foi considerado o rendimento do peito inteiro com pele e ossos, asas e pernas (coxa e sobrecoxa com ossos e pele), que foram calculados em relação ao peso da carcaça eviscerada.

Os dados obtidos de cada parâmetro dos níveis de lisina digestível foram desdobrados em polinômios ortogonais de forma a permitir a análise de variância e regressão de acordo com suas distribuições. Para compará-los foram usados dois controles: alta e baixa proteína bruta, em que foram submetidos ao teste de Dunnet 5\%, utilizando o programa estatístico Saeg (UFV 1997).

\section{RESULTADOS}

Pela análise de regressão, excluindo as dietas-controle de baixa e alta proteína bruta, observou-se efeito das dietas com nucleotídeos de acordo com os níveis de lisina digestível, para consumo (CR) e conversão alimentar (CA) de 20 a 27,20 a 35 e 20 a 42 dias (Quadro 2). 0 consumo alimentar (g) apresentou efeito linear decrescente onde, aumentan- do os níveis de lisina digestível na dieta, observou-se diminuição no consumo de ração. A conversão alimentar (g/g) apresentou efeito quadrático para as aves de 20 a 27, 20 a 35 e para 20 a 42 dias de idade, diminuindo à medida que os níveis de lisina digestível aumentaram, atingindo o mínimo com 1,119\%, 1,187\% e 1,132\% de lisina digestível, respectivamente.

Para comparar as dietas de níveis de lisina digestível com os grupos-controle, usou-se o teste de Dunnet a $5 \%$ de probabilidade. Em relação ao controle com alta proteína bruta $(18,86 \%)$ sem nucleotídeos com as dietas de baixa proteína bruta com adição nucleotídeos. (Quadro 2), o peso vivo (g) aos 27 dias de idade foi maior para as aves que consumiram a dieta-controle $(18,86 \% \mathrm{~PB})$, porém aos 35 dias de idade, as dietas com os níveis de 1,062 \% e 1,262\% de lisina digestível, ambas de baixa proteína, com 0,5 kg de Ascogen/ton, foram semelhantes à dieta-controle. 0 consumo de ração foi maior apenas para o tratamento com $0,862 \%$ de lisina digestível. A dieta controle obteve conversão alimentar menor em todas as idades. 
Analisando o controle sem nucleotídeos e 16,80\% de $\mathrm{PB}$, com as dietas de baixa proteína bruta com adição nucleotídeos (Quadro 2), o consumo de ração (g) da dieta com $1,162 \%$ de lisina digestível, para 20-27 dias e 20-35 dias de idade foi menor $(\mathrm{P} \leq 0,05)$ do que a dieta-controle testada, fato este não observado para as outras dietas. Na conversão alimentar apenas o menor nível de lisina digestível - 0,862\% - diferiu da dieta-controle, apresentando a pior conversão alimentar.

Os dados referentes à morfologia intestinal encontram-se nos Quadros 3, 4 e 5. Não foram encontrados resultados significativos para as variáveis: comprimento do intestino $(\mathrm{cm})$ e peso relativo do intestino, baço, bolsa cloacal e fígado. Aos 35 dias, pela análise de regressão, a relação entre vilosidade e cripta no duodeno teve efeito linear. A altura das vilosidades e profundidade de cripta, também no duodeno, apresentou efeito quadrático onde atingiram o máximo com $0,983 \%$ e $1,211 \%$ de lisina digestível, respectivamente.

Para comparar os tratamentos de níveis de lisina, com os grupos-controle de alta e baixa proteína bruta, usou-se o teste de Dunnet a 5\% de probabilidade. A dieta com 1,062\% de lisina digestível (Quadro 4) não diferiu $(\mathrm{P}>0,05)$ do controle com alta proteína, para altura das vilosidades e profundidade de cripta no duodeno, assim como foi maior para a altura das vilosidades no jejuno.

Na comparação entre os tratamentos com níveis de lisina e a dieta-controle com baixa proteína (Quadro 4), houve diferença $(\mathrm{P}<0,05)$ entre o controle e a dieta com $1,062 \%$ de lisina digestível para altura das vilosidades e profundidade de cripta no duodeno e para a altura das vilosidades no jejuno.

Não houve efeito de inclusão de nucleotídeos para rendimento de carcaça e cortes nobres (Quadro 5). Os resultados deste experimento demonstraram que frangos de corte criados sem desafio e recebendo dieta adequadamente balanceada podem expressar todo seu potencial genético para rendimento de carcaça e partes independente da suplementação com nucleotídeos.

Quadro 2. Peso vivo (PV), ganho de peso (GP), consumo(CR) e conversão alimentar(CA) de frangos de corte, aos 42 dias de idade, alimentados com dietas contendo diferentes níveis de lisina digestível, com nucleotídeos, comparados com as dietas-controle

\begin{tabular}{|c|c|c|c|c|c|c|c|c|c|c|}
\hline & \multicolumn{2}{|c|}{ Controle } & \multirow{2}{*}{\multicolumn{5}{|c|}{$\begin{array}{l}\text { 16,80\% PB + nucleotideos } \\
\text { Níveis de lisina digestível }\end{array}$}} & \multicolumn{3}{|c|}{ Efeito } \\
\hline & \multirow{2}{*}{$\begin{array}{c}\text { 18,86\% PB } \\
\text { (sem } \\
\text { nucleotídeos) }\end{array}$} & \multirow{2}{*}{$\begin{array}{c}\text { 16,80\% PB } \\
\text { (sem } \\
\text { nucleotídeos) }\end{array}$} & & & & & & \multirow[t]{2}{*}{$\mathrm{CV}(\%)$} & \multirow[t]{2}{*}{$\mathrm{L}$} & \multirow[t]{2}{*}{ Q } \\
\hline & & & $0,862 \%$ & $0,962 \%$ & $1,062 \%$ & $1,162 \%$ & $1,262 \%$ & & & \\
\hline \multicolumn{11}{|l|}{ GP (g) } \\
\hline 20 a 27 dias & $550,00 \pm 0,67$ & $520,09 \pm 0,67$ & $510,07 \pm 0,33$ & $520,19 \pm 0,35$ & $530,09 \pm 0,30$ & $510,15 \pm 0,55$ & $520,00 \pm 0,41$ & 2,74 & 0,159 & 0,120 \\
\hline 20 a 35 dias & $1240,11 \pm 0,18$ & $1190,14 \pm 0,45$ & $1160,44 \pm 0,49$ & $1160,81 \pm 0,37$ & $1200,17 \pm 0,31$ & $1160,12 \pm 0,27$ & $1190,18 \pm 0,44$ & 3,02 & 0,389 & 0,642 \\
\hline $\begin{array}{l}20 \text { a } 42 \text { dias } \\
\text { CR(g) }\end{array}$ & $1899,97 \pm 0,10$ & $1790,21 \pm 0,48$ & $1770,23 \pm 0,41$ & $1810,20 \pm 0,42$ & $1830,00 \pm 0,40$ & $1760,06 \pm 0,39$ & $1800,25 \pm 0,55$ & 2,77 & 0,442 & 0,645 \\
\hline 20 a 27 dias & $910,09 \pm 0,21^{\mathrm{a}}$ & $920,06 \pm 0,24^{\mathrm{A}}$ & $940,12 \pm 0,27^{\mathrm{aA}}$ & $900,18 \pm 0,51^{\mathrm{aA}}$ & $920,09 \pm 0,29^{\mathrm{aA}}$ & $890,32 \pm 0,25^{\mathrm{aB}}$ & $900,47 \pm 0,30^{\mathrm{aA}}$ & 2,30 & 0,001 & 0,754 \\
\hline 20 a 35 dias & $2120,45 \pm 0,15^{a}$ & $2150,50 \pm 0,12^{\mathrm{A}}$ & $2180,46 \pm 0,19^{\mathrm{bA}}$ & $2090,11 \pm 0,67^{\mathrm{aA}}$ & $2140,04 \pm 0,38^{\mathrm{aA}}$ & $2070,27 \pm 0,30^{\mathrm{aB}}$ & $2110,63 \pm 0,29^{\mathrm{aA}}$ & 2,18 & 0,001 & 0,365 \\
\hline 20 a 42 dias & $3490,11 \pm 0,33^{a}$ & $3530,33 \pm 0,49^{A}$ & $3630,14 \pm 0,25^{\mathrm{bA}}$ & $3520,00 \pm 0,58^{\mathrm{aA}}$ & $3600,17 \pm 0,15^{\mathrm{aA}}$ & $3430,55 \pm 0,61^{\mathrm{aB}}$ & $3520,22 \pm 0,59^{\mathrm{aA}}$ & 1,95 & 0,002 & 0,152 \\
\hline \multicolumn{11}{|c|}{ (1) } \\
\hline 20 a 27 dias & $1,641 \pm 0,36^{a}$ & $1,770 \pm 0,66^{A}$ & $1,858 \pm 0,39^{\text {bв }}$ & $1,735 \pm 0,46^{\mathrm{bA}}$ & $1,754 \pm 0,07^{\mathrm{bA}}$ & $1,749 \pm 0,12^{\mathrm{bA}}$ & $1,755 \pm 0,54^{\mathrm{bA}}$ & 2,74 & 0,987 & 0,001 \\
\hline 20 a 35 dias & $1,704 \pm 0,07^{a}$ & $1,804 \pm 0,04^{\mathrm{A}}$ & $1,884 \pm 0,50^{\mathrm{bB}}$ & $1,809 \pm 0,48^{\mathrm{bA}}$ & $1,795 \pm 0,25^{\mathrm{bA}}$ & $1,781 \pm 0,27^{\mathrm{bA}}$ & $1,775 \pm 0,44^{\mathrm{bA}}$ & 3,02 & 0,524 & 0,000 \\
\hline 20 a 42 dias & $1,875 \pm 0,03^{a}$ & $1,982 \pm 0,50^{\mathrm{A}}$ & $2,005 \pm 0,55^{\mathrm{bB}}$ & $1,948 \pm 0,29^{\mathrm{bA}}$ & $1,966 \pm 0,30^{\mathrm{bA}}$ & $1,945 \pm 0,50^{\mathrm{bA}}$ & $1,958 \pm 0,57^{\mathrm{bA}}$ & 2,77 & 0,497 & 0,003 \\
\hline
\end{tabular}

Regressão

$\hat{Y} C R 20-27$ dias $=0,995-0,000076 \times$ R $2=0,57$
$\hat{Y} C R 20-35$ dias $=2,308-0,0000175 \times$ R $2=0,68$

ŶCR 20-42 dias $=3,869-0,000307 \times$ R $2=0,62$

ŶCA 20-27 dias $=3,826-3,742+1,671 \times 2$ R2 $=0,56$ / ponto de mínimo=1,119\% Lisina digestível

ŶCA $20-35$ dias $=3,176-2,364 \mathrm{x}+0,996 \times 2 \mathrm{R} 2=0,65$ / ponto de mínimo $=1,187 \%$ Lisina digestível

$\hat{\mathrm{Y} C A} 20-42$ dias $=3,768-3,234 \mathrm{x}+1,429 \times 2 \mathrm{R} 2=0,50 /$ ponto de mínimo=1,132\% Lisina digestível

\begin{abstract}
* Letras minúsculas diferentes na mesma linha diferem significativamente pelo teste de Dunnet $(\mathrm{P} \leq 0,05)$ da dieta com $18,86 \% \mathrm{~PB}$ com as demais dietas. Letras maiúsculas diferentes na mesma linha diferem significativamente pelo teste de Dunnet $(\mathrm{P} \leq 0,05)$ da dieta com $16,80 \% \mathrm{~PB}$ com as demais dietas. CV = Coeficiente de Variação; Efeito L = linear; $Q$ = quadrático; CONS = consumo alimentar; CA = conversão alimentar.
\end{abstract}

Quadro 3. Valores médios do comprimento do intestino delgado e dos órgãos do trato gastrintestinal de frangos de corte com 35 dias de idade, alimentados com dietas contendo diferentes níveis de lisina digestível, com ou sem adição de nucleotídeos

\begin{tabular}{|c|c|c|c|c|c|c|c|c|}
\hline & \multicolumn{2}{|c|}{ Controle } & \multicolumn{5}{|c|}{ 16,80\% PB + nucleotídeos } & \multirow[t]{3}{*}{$\mathrm{CV}(\%)$} \\
\hline & \multirow{2}{*}{$\begin{array}{c}\text { 18,86\% } \\
\text { (sem } \\
\text { nucleotídeos) }\end{array}$} & \multirow{2}{*}{$\begin{array}{c}16,80 \% \mathrm{~PB} \\
\text { (sem } \\
\text { nucleotídeos) }\end{array}$} & \multicolumn{5}{|c|}{ Níveis de lisina digestível } & \\
\hline & & & $0,862 \%$ & $0,962 \%$ & $1,062 \%$ & $1,162 \%$ & $1,262 \%$ & \\
\hline Peso vivo (g) & $2.043,43 \pm 0,25$ & $2.103,71 \pm 0,19$ & $1.974,57 \pm 0,29$ & $1.964,00 \pm 0,16$ & $2.010,29 \pm 0,41$ & $2.064,86 \pm 0,30$ & $2.034,00 \pm 0,21$ & 5,24 \\
\hline Comp.intestino $(\mathrm{cm})$ & $156,57 \pm 0,12$ & $167,71 \pm 0,14$ & $163,71 \pm 0,09$ & $163,62 \pm 0,16$ & $161,00 \pm 0,26$ & $155,00 \pm 0,24$ & $166,37 \pm 0,13$ & 9,78 \\
\hline Intestino (\%) & $4,83 \pm 0,36$ & $4,66 \pm 0,29$ & $4,89 \pm 0,42$ & $4,96 \pm 0,20$ & $4,35 \pm 0,41$ & $4,34 \pm 0,36$ & $4,51 \pm 0,44$ & 14,83 \\
\hline Baço (\%) & $0,12 \pm 0,09$ & $0,11 \pm 0,05$ & $0,13 \pm 0,15$ & $0,10 \pm 0,16$ & $0,11 \pm 0,10$ & $0,11 \pm 0,10$ & $0,12 \pm 0,31$ & 25,30 \\
\hline Bolsa cloacal (\%) & $0,21 \pm 0,57$ & $0,17 \pm 0,62$ & $0,21 \pm 0,40$ & $0,22 \pm 0,44$ & $0,18 \pm 0,39$ & $0,18 \pm 0,55$ & $0,17 \pm 0,39$ & 31,35 \\
\hline Fígado (\%) & $2,32 \pm 0,61$ & $2,40 \pm 0,52$ & $2,43 \pm 0,32$ & $2,29 \pm 0,66$ & $2,02 \pm 0,37$ & $2,37 \pm 0,60$ & $2,33 \pm 0,37$ & 15,43 \\
\hline
\end{tabular}

$\overline{\mathrm{CV}}=$ Coeficiente de variação. 
Quadro 4. Altura das vilosidades (AV) $(\mu \mathrm{m})$, profundidade das criptas (PC) $(\mu \mathrm{m})$ e relação vilo:cripta (AV:PC), dos segmentos do intestino delgado de frangos de corte, aos 35 dias de idade, alimentados com dietas contendo diferentes níveis de lisina digestível, com nucleotídeo, comparados com as dietas-controle1

\begin{tabular}{|c|c|c|c|c|c|c|c|c|c|c|}
\hline & \multicolumn{2}{|c|}{ Controle } & \multirow{2}{*}{\multicolumn{5}{|c|}{$\begin{array}{c}\text { 16,80\% PB + Nucleotideos } \\
\text { Níveis de Lisina Digestível }\end{array}$}} & \multicolumn{3}{|c|}{ Efeito } \\
\hline & $\begin{array}{c}\text { 18,86\%PB } \\
\text { (sem } \\
\text { nucleotídeos) }\end{array}$ & $\begin{array}{c}\text { 16,80\% PB } \\
\text { (sem } \\
\text { nucleotídeos) }\end{array}$ & & & & & & $\mathrm{CV}(\%)$ & $\mathrm{L}$ & $Q$ \\
\hline $\mathrm{AV}$ & $1916,16 \pm 35,78^{\mathrm{a}}$ & $1499,53 \pm 44,32^{\mathrm{A}}$ & $1706,26 \pm 20,89^{\text {вв }}$ & $1687,36 \pm 17,31^{\mathrm{bA}}$ & ${ }^{\mathrm{A}} 2010,57 \pm 20,24^{\mathrm{aB}}$ & $1332,85 \pm 39,59^{\mathrm{b} /}$ & $1273,39 \pm 20,77^{\mathrm{bA}}$ & 20,27 & 0,234 & 0,001 \\
\hline PC & $264,99 \pm 6,33^{\mathrm{a}}$ & $243,33 \pm 5,97^{\mathrm{A}}$ & $177,47 \pm 7,54^{\mathrm{bA}}$ & $242,76 \pm 7,80^{\mathrm{aA}}$ & $291,15 \pm 12,19^{а в ~}$ & $208,76 \pm 2,17^{\mathrm{bA}}$ & $293,01 \pm 6,32^{\text {bB }}$ & 42,69 & 0,199 & 0,002 \\
\hline $\begin{array}{l}\text { AV:PC } \\
\text { Jejuno }\end{array}$ & $7,56 \pm 0,17^{a}$ & $6,51 \pm 0,22^{A}$ & $12,75 \pm 0,74^{\mathrm{bB}}$ & $7,97 \pm 0,16^{\mathrm{aA}}$ & $8,17 \pm 0,27^{\text {ав }}$ & $6,46 \pm 0,20^{\mathrm{bA}}$ & $4,55 \pm 0,12^{\mathrm{bB}}$ & 47,55 & 0,000 & 0,224 \\
\hline PC & $203,03 \pm 4,93^{\mathrm{a}}$ & $211,89 \pm 6,96^{\mathrm{A}}$ & $205,52 \pm 4,31^{\mathrm{aB}}$ & $202,50 \pm 4,64^{\mathrm{aB}}$ & $213,96 \pm 8,82^{\mathrm{bA}}$ & $152,22 \pm 5,77^{\mathrm{bA}}$ & $204,76 \pm 6,01^{\mathrm{aB}}$ & 33,52 & 0,089 & 0,191 \\
\hline $\begin{array}{l}\text { AV:PC } \\
\text { Íleo }\end{array}$ & $4,90 \pm 0,09^{a}$ & $5,15 \pm 0,14^{\mathrm{A}}$ & $6,35 \pm 0,13^{\mathrm{bA}}$ & $4,65 \pm 0,09^{\mathrm{aB}}$ & $7,36 \pm 0,26^{\mathrm{bB}}$ & $7,36 \pm 0,26^{\mathrm{bB}}$ & $5,18 \pm 0,18^{\mathrm{aA}}$ & 33,38 & 0,036 & 0,111 \\
\hline $\mathrm{AV}$ & 586,88 & 572,39 & 603,1 & $\pm 5,19$ & 746,1 & 68 & 53 & 22,63 & 0,874 & 0,15 \\
\hline PC & $157,84 \pm 5,29$ & $135,32 \pm 5,31$ & $145,42 \pm 4,62$ & $91,17 \pm 1,23$ & $146,32 \pm 6,82$ & $151,15 \pm 3,67$ & $127,26 \pm 4,49$ & 38,32 & 1,125 & 0,564 \\
\hline AV:PC & $4,10 \pm 0,14$ & $4,79 \pm 0,16$ & $4,54 \pm 0,13$ & $5,36 \pm 0,14$ & $6,14 \pm 0,19$ & $4,79 \pm 0,11$ & $4,32 \pm 0,14$ & 32,77 & 0,965 & 0,235 \\
\hline
\end{tabular}

* Letras minúsculas diferentes na mesma linha diferem significativamente pelo teste de Dunnet $(\mathrm{P} \leq 0,05)$ da dieta com $18,86 \% \mathrm{~PB}$ com as demais dietas. Letras maiúsculas diferentes na mesma linha diferem significativamente pelo teste de Dunnet $(\mathrm{P} \leq 0,05)$ da dieta com $16,80 \% \mathrm{~PB}$ com as demais dietas. CV = Coeficiente de Variação; Efeito L = linear; Q = quadrático; CONS = consumo alimentar; CA = conversão alimentar.

Quadro 5. Valores percentuais médios de rendimento de carcaça e cortes nobres, de frangos de corte aos 42 dias de idade, alimentos com dietas contendo diferentes níveis de lisina digestível, com ou sem adição de nucleotídeos

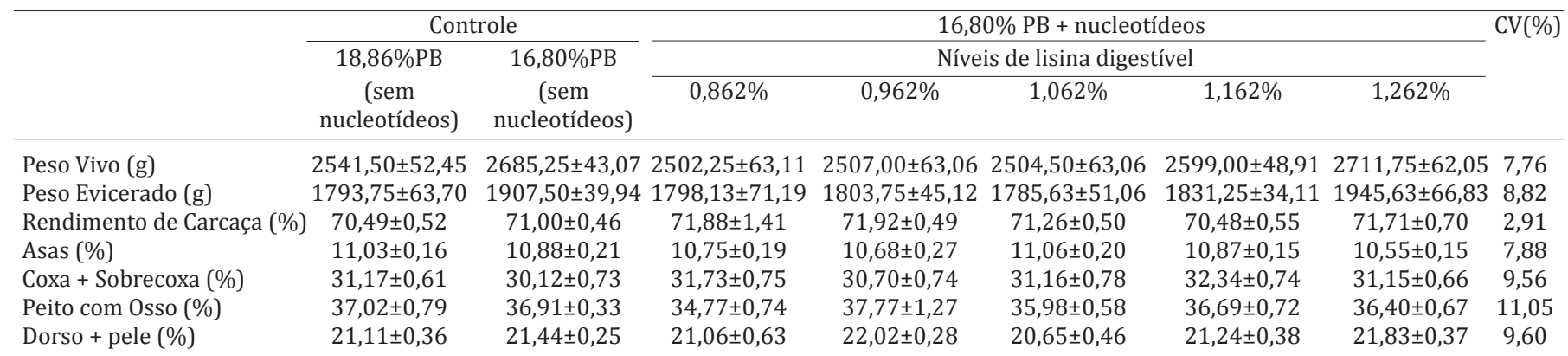

$\mathrm{CV}=$ Coeficiente de variação.

\section{DISCUSSÃO}

De acordo com os dados apresentados, a utilização de nucleotídeos complementa a baixa porcentagem de proteína das rações experimentais, evidenciando efeito benéfico do uso de nucleotídeos na dieta do frango de corte.

Para atender ao aporte de nutrientes requisitado diariamente, o animal aumenta ou diminui o consumo da dieta até que esse requerimento seja suprido. No tratamento com $0,862 \%$ de lisina digestível, os animais também estavam consumindo uma menor porcentagem de proteína digestível, o aumento do consumo foi uma reação dos animais para alcançarem suas exigências nutricionais. Tal fato pode ser explicado pela lisina ser um aminoácido limitante, ou seja, sua redução, no caso abaixo do recomendado para um ótimo desenvolvimento da ave, também compromete o balanceamento de outros aminoácidos, aumentando os valores de CA, entre outras variáveis.

A adição de nucleotídeos nas rações com baixa porcentagem de proteína bruta mostrou ser benéfica ao consumo de ração, pois não se diferenciou dos valores encontrados no controle de alta proteína sem o aditivo e também, ao ganho de peso, onde não houve diferença entre os tratamentos. Os dados encontrados concordam com Rutz et al. (2006), em que observaram melhora no desempenho de frangos de corte ao fornecerem extrato de leveduras aos animais e atribuíram o melhor desempenho, ao efeito benéfico dos nucleotídeos presentes no extrato de leveduras. Por outro lado, Zavarize et al. (2007) não observaram melhora no desempenho de frangos de corte recebendo dieta suplementada com $0,05 \%$ nucleotídeos quando comparado aos animais que receberam dieta não suplementada.

A adição de nucleotídeo mostrou ser vantajosa para a redução da PB (\%) da ração, pois os resultados encontrados podem ter sido ocasionados pela melhora na integridade intestinal das aves, pois as dietas continham a mesma porcentagem de lisina digestível e proteína bruta. As divisões mitóticas nas criptas respondem por cerca de $60 \%$ da proliferação celular, a região média dos vilos por $32 \%$ e a região apical por 8\% (Herdt et al. 2004). Esses dados são muito importantes do ponto de vista funcional do intestino das aves, já que aproximadamente $50 \%$ da proliferação celular no intestino das mesmas podem ocorrer ao longo dos vilos. 
Tamanho e densidade das vilosidades estão diretamente relacionados com perda de células (extrusão) e renovação celular (turnover) pelo epitélio da mucosa intestinal (Maiorka et al. 2002). 0 equilíbrio entre esses dois processos determina um turnover constante, ou seja, a manutenção do tamanho dos vilos e, portanto a manutenção da capacidade digestiva e de absorção intestinal. Além disso, para maximizar o desempenho das aves é muito importante a preservação da integridade morfofuncional do sistema digestório.

Com a suplementação de nucleotídeos em dietas de baixa proteína com $1,062 \%$ de lisina digestível é possível manter a integridade intestinal e o desempenho de frangos de corte.

\section{REFERÊNCIAS}

Bertechini A.G. 2006. Nutrição de monogástricos. Ed. Ufla, Lavras. 301p.

Bueno J., Torres M., Alemdros A., Carmona R., Nunex M.C. \& Rios A. 1994. Effect of dietary nucleotides on small intestinal repair after diarrhea: histological and ultrastructural changes. Gut 35:926-933.

Herdt T. \& Cunningham J.G. 2004. Fisiologia gastrintestinal de metabolismo, p.231-238. In: Ibid. (Eds), Tratado de Fisiologia Veterinária. Guanabara Koogan, Rio de Janeiro. 720p.

Loddi M.M. 1998. Aspectos produtivos e qualitativos do uso de probiótico para frangos de corte. Dissertação de Mestrado, Universidade Estadual Paulista, Botucatu, SP. 60p.

Maiorka A., Boleli I.C. \& Macari M. 2002. Desenvolvimento e reparo da mucosa intestinal, p.113-123. In: Macari M., Furlan R.L. \& Gonzales E. (Eds), Fisiologia Aviária Aplicada a Frangos de Corte. Funep/Unesp, Jaboticabal. 375p.

Mateo C.D. \& Stein H.H. 2004. Nucleotides and young animal health: can we enhance intestinal tract development and immune function? Nutrition Biotechnology in the Feed Industry: Proceedings of Alltech's 20th Annual Symposium, Lexington, KY, p.159-170.

Rostagno H.S., Albino L.F.T. \& Donzele J.L. 2005. Tabelas Brasileiras para Aves e Suínos: composição de alimentos e exigências nutricionais. $2^{\underline{a}}$ ed. UFV, Viçosa. 186p.

Rutz F., Anciuti M.A., Rech J.L., Gonçalves F.M., Delgado A.D., Rosa E.R., Zauki N., Ribeiro C.L.G., Silva R.R. \& Dallmann P.R. 2006. Desempenho e características de carcaças de frangos de corte recebendo extrato de levedura na dieta. Ciênc. Anim. Bras. 7:349-355.

Turner J.L., Dritz S.S. \& Minton J.E. 2001. Alternatives to conventional antimicrobials in swine diets. Prof. Anim. Sci. 17:217-226.

Uni Z. 2000. Vitamin A deficiency interferes with proliferation and maturation of cells in the chickens small intestine. Brit. Poult. Sci. 41:410-415.

UFV 1997. SAEG - Sistema de Análises Estatísticas e Genéticas. Versão 5.0. Universidade Federal de Viçosa, Viçosa, MG. 150p.

Zavarize K.C., Sartori J.R. \& Pelícia V.C. 2007. Desempenho de frangos de corte criados no sistema alternativo suplementados com L-glutamina e nucleotídeos. I Conferência APINCO de Ciência e Tecnologia Avícolas, Campinas. FACTA, Campinas, p.113-113. 